\title{
A Novel Role for Protein Synthesis in Long-Term Neuronal Plasticity: Maintaining Reduced Postburst Afterhyperpolarization
}

\author{
Sivan Ida Cohen-Matsliah, ${ }^{\star}$ Helen Motanis, ${ }^{\star}$ Kobi Rosenblum, and Edi Barkai \\ Departments of Neurobiology and Biology, Faculty of Sciences, University of Haifa, Haifa 31905, Israel
}

\begin{abstract}
Memory consolidation, the process of transformation of short-term to long-term memory, has been shown to be protein synthesis dependent in a variety of different learning paradigms, brain structures, and species. At the cellular level, protein synthesis was shown to be crucial for induction of long-term synaptic plasticity; application of protein synthesis inhibitors prevents the transformation of early long-term potentiation (LTP) to late LTP. Thus, protein synthesis has been traditionally thought to affect long-term memory consolidation by stabilizing synaptic transmission. However, long-term memory is not supported only by modulation of synaptic strength; modifications in intrinsic neuronal properties also subserve learning-related behavioral changes. Learning-induced reduction in the postburst afterhyperpolarization (AHP), which results with enhanced neuronal excitability and decreased spike frequency adaptation, is apparent in hippocampal and cortical pyramidal neurons. Such postburst AHP reduction lasts for days after training completion and is implicated in maintaining learned skills. Short-term modulation of intrinsic neuronal excitability can be also induced in vitro. Intense synaptic activation induces AHP reduction and enhanced neuronal excitability in hippocampal pyramidal neurons. Here, we show that synaptic activation-induced short-term postburst AHP reduction can be transformed to long-term AHP reduction, such that persists for prolonged time periods. This long-lasting AHP reduction is protein synthesis dependent for up to $1 \mathrm{~h}$ after induction. We suggest that, much like synaptic plasticity, activity-induced long-lasting modulation of intrinsic neuronal excitability requires molecular consolidation. It would appear that both synaptic and intrinsic modifications and maintenance are activated jointly to enable long-lasting memories.
\end{abstract}

\section{Introduction}

Memory can be divided according to different temporal phases: acquisition, consolidation, and retrieval. The consolidation phase is divided into molecular consolidation (range of hours after acquisition) and system consolidation (range of weeks and months after acquisition) (Dudai, 2004). Molecular consolidation is thought to be a protein synthesis-dependent process (Alberini, 2008; Costa-Mattioli et al., 2009). The clear effect of protein synthesis inhibitors on long-term memory was studied extensively mainly in the context of late-phase long-term potentiation (LTP) (Abraham and Williams, 2008). Similar molecular mechanisms were proposed for maintenance of long-term synaptic modifications and learning processes (Davis and Squire, 1984; Costa-Mattioli et al., 2009). However, long-term memory is not supported only by modulation of synaptic strength; modifications in intrinsic neuronal properties also subserve learningrelated behavioral changes (Saar and Barkai, 2003; Zhang and Linden, 2003; Disterhoft et al., 2004). Thus, the question arises

\footnotetext{
Received 0ct. 8, 2009; revised Nov. 15, 2009; accepted Dec. 11, 2009.

This work was supported by grants from the United States-Israel Binational Science Foundation and the Israel Science Foundation (E.B.).

*S.I.C.-M. and H.M. contributed equally to this work.

Correspondence should be addressed to Dr. Edi Barkai, Department of Biology, Faculty of Sciences, Haifa University, Haifa 31905, Israel. E-mail: ebarkai@research.haifa.ac.il.

DOI:10.1523/JNEUROSCI.5005-09.2010

Copyright $\odot 2010$ the authors $\quad 0270-6474 / 10 / 304338-05 \$ 15.00 / 0$
}

whether protein synthesis inhibitors affect memory consolidation via additional neuronal processes, such as modification and maintenance of neuronal excitability.

Learning-induced enhancement in neuronal excitability has been detected in hippocampal neurons following various training paradigms, such as classical conditioning of the trace eyeblink response (Moyer et al., 1996; Thompson et al., 1996), Morris water maze task (Oh et al., 2003), and olfactory-discrimination learning (Zelcer et al., 2006). Learning-induced enhanced excitability is manifested in reduced spike frequency adaptation in response to prolonged depolarizing current applications, which lasts for periods of days after learning (Moyer et al., 1996; Thompson et al., 1996; Saar and Barkai, 2003; Zelcer et al., 2006).

Neuronal adaptation is modulated by the postburst afterhyperpolarization (AHP), generated by potassium currents that develop after spike firing (Madison and Nicoll, 1984; Schwindt et al., 1988). This postburst AHP is reduced after learning (Moyer et al., 1996; Saar et al., 1998). Several studies indicate that the learning-induced reduction in neuronal adaptation and in AHP amplitude result from reduction in a $\mathrm{Ca}^{2+}$-dependent potassium current (Power et al., 2002; Saar and Barkai, 2003). In particular, it has been suggested that changes in the ${ } I_{\mathrm{AHP}}$ current may account for learning-related intrinsic modifications in hippocampal and cortical neurons (Oh et al., 2003; Brosh et al., 2006).

Short-term reduction in the postburst AHP can be induced also in vitro, much like early LTP, by repetitive tetanic synaptic 

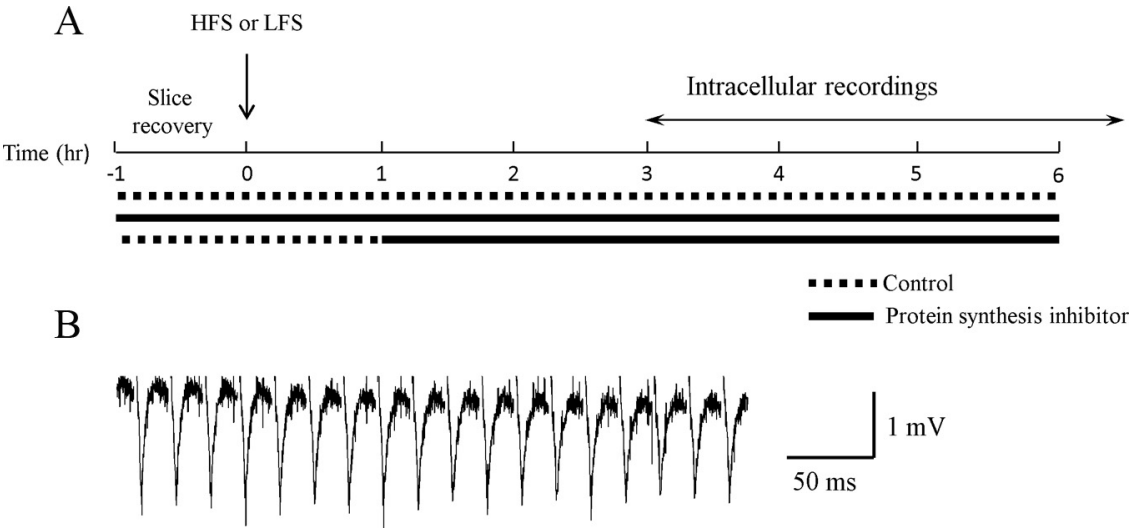

Figure 1. Experimental protocols and synaptic responses. $\boldsymbol{A}$, Protocols of synaptic stimulation and protein synthesis inhibitor (anisomycin or cycloheximide) application. HFS or LFS was applied at time 0 . The dotted line notes recording time in protein synthesis inhibitor-free solution, and the continuous line notes recording time with the protein synthesis inhibitor. Stimulation protocols for the three groups that were exposed to HFS [HFS-only, Ani-plus-HFS (or Cyclo-plus-HFS), and Ani-after-HFS] and the LFS group are presented. $\boldsymbol{B}$, Typical synaptic responses to 20 stimuli delivered at $50 \mathrm{~Hz}$. Stimulation electrode was placed in the Schaffer collaterals and the recording electrode in the CA1 cell body layer. Stimulus intensity was adjusted to evoke a fPSP with amplitude of $1-2 \mathrm{mV}$.

stimulation (Melyan et al., 2002). A similar effect is obtained by briefly exposing these neurons to kainate (Melyan et al., 2004).

The purpose of the present study was to explore whether long-term AHP reduction can be also induced by synaptic activation. Moreover, since late LTP is protein synthesis dependent (Krug et al., 1984; Otani et al., 1989; Manahan-Vaughan et al., 2000; Rosenblum et al., 2002; Sajikumar and Frey, 2003), we tested whether a similar obligatory role exists for protein synthesis in long-term induction of AHP reduction.

We show that synaptic activation-induced AHP reduction lasts for many hours, well into the range in which late LTP occurs and that the induction of such long-lasting reduction is protein synthesis dependent, at a specific well defined time window after synaptic activation.

\section{Materials and Methods}

Slice preparation, stimulation, and recording. Hippocamal slices were prepared from young adults (aged 2 months) Sprague Dawley male rats. Four hundred micrometer coronal brain slices were cut from the dorsal hippocampus and kept in oxygenated $\left(95 \% \mathrm{O}_{2}\right.$ plus $\left.5 \% \mathrm{CO}_{2}\right)$ Ringer's solution (in mm: $124 \mathrm{NaCl}, 3 \mathrm{KCl}, 2 \mathrm{MgSO}_{4}, 1.25 \mathrm{NaH}_{2} \mathrm{PO}_{4}, 26 \mathrm{NaHCO}_{3}$, $2 \mathrm{CaCl}_{2}$, and 10 glucose).

Intracellular recordings were performed from CA1 pyramidal neurons at $36^{\circ} \mathrm{C}$, with $4 \mathrm{M} \mathrm{K}$-acetate-filled sharp glass microelectrodes. Cell input resistance $\left(R_{\text {in }}\right)$ was determined by linear regression fit to a voltage/ current curve at the range from resting potential to $-15 \mathrm{mV}$ from resting. Spike width was measured at the spike threshold.

Synaptic stimulation. Synaptic stimulation was delivered via a bipolar tungsten electrode, positioned at the Schaffer collaterals, to activate the glutamatergic synapses onto CA1 pyramidal neurons. Stimulus intensity was adjusted to evoke a field postsynaptic potential (fPSP) with amplitude of $1-2 \mathrm{mV}$.

Activity-induced AHP reduction was induced by applying highfrequency stimulation (HFS); 20 repetitive stimuli were applied at $50 \mathrm{~Hz}$. Only slices in which the fPSP was stable for all stimuli in the train (see Fig. $1 B$ ) were used. After HFS, slices were kept without additional activation for $3 \mathrm{~h}$ before intracellular recordings were attempted. Such subsequent AHP recordings were performed in the vicinity of the fPSP recording site. Low-frequency simulation (LFS) was applied with the same number of synaptic stimuli (20) at the frequency of $1 \mathrm{~Hz}$.

Stimulating repetitively in these conditions did not induce LTP of the synaptic response; $1 \mathrm{~h}$ after repetitive stimulation, the averaged value of the fPSP was similar to that recorded before repetitive stimulation (ratio of synaptic responses before and after stimuli application, $1.09 \pm 0.19 ; n=9 ; p=0.72$ ).

Postburst AHP measurements. To standardize AHP recordings, cell membrane potential was depolarized to $-60 \mathrm{mV}$ with DC current application via the recording electrode, and AHP amplitude was measured after an additional $100 \mathrm{~ms}$ depolarizing current step that generated six action potentials, after which the DC depolarization was maintained. AHP amplitude was determined from an average of $8-10$ consecutive responses to stimuli applied once every $10 \mathrm{~s}$. Under these conditions, a postburst AHP that lasted up to several seconds appeared in all CA1 pyramidal neurons. The stimulus intensity applied to evoke a burst of six action potentials on the 100-ms-long depolarizing pulse was adjusted to ensure that the last spike in the train would be evoked 10-15 $\mathrm{ms}$ before the end of the pulse. This procedure was undertaken to ensure that the firing frequency would be similar in neurons from all groups, so that the postburst AHP would not be affected by the firing frequency of the six action potential train.

Drug application. Protein synthesis inhibitors, anisomycin (10 $\mu \mathrm{M}$; Sigma-Aldrich) and cycloheximide (60 $\mu \mathrm{m}$; Fluka), were applied into the perfusing Ringer's solution. Slices were exposed to drugs either immediately after slice preparation or $1 \mathrm{~h}$ after repetitive synaptic stimulation. One neuron was recorded for each slice.

Statistical analysis. Between-group comparison was done using oneway ANOVA, and post hoc multiple nondirectional $t$ tests were then applied to compare between each two groups. Values throughout the text are presented as mean $\pm \mathrm{SD}$. Data in graphs are presented as mean $\pm \mathrm{SE}$.

\section{Results}

Postburst AHP recordings were performed in 75 CA1 pyramidal neurons divided into seven groups (Fig. 1A): (1) control neurons that were not submitted to synaptic activation; (2) neurons that were recorded several hours after high-frequency synaptic stimulation ("HFS only"); (3) neurons that were recorded several hours after low-frequency synaptic stimulation ("LFS only"); (4, 5 ) neurons from slices that were treated with anisomycin or cycloheximide during HFS application ("Ani plus HFS" and "Cyclo plus HFS"); (6) neurons from slices that were exposed to anisomycin, without synaptic stimulation ("Ani only"); and (7) neurons from slices that were exposed to anisomycin $1 \mathrm{~h}$ after HFS application ("Ani after HFS"). The averaged amplitudes of the evoked field potentials was similar for the groups to which synaptic stimulation was applied [HFS, $1.4 \pm 0.4 \mathrm{mV}(n=12)$; Ani plus HFS, $1.13 \pm 0.3 \mathrm{mV}(n=12)$; Ani after HFS, $1.29 \pm 0.5 \mathrm{mV}$ $(n=11) ; p=0.88]$. Population spikes were not evident in any of the synaptic responses. The averaged value of the intensity of the current applied via the recording electrode to evoke six action potentials was also similar for all experimental groups [control, $0.61+0.19 \mathrm{nA}(n=16) ; \mathrm{HFS}, 0.65+0.17 \mathrm{nA}(n=12)$; Ani plus HFS, $0.63+0.16 \mathrm{nA}(n=12)$; Ani only, $0.74+0.28 \mathrm{nA}(n=24)$; Ani after HFS, $0.79+0.23 \mathrm{nA}(n=11) ; p=0.29]$.

\section{HFS-induced long-term AHP reduction}

We first examined whether repetitive synaptic stimulation results with postburst AHP reduction, such that would be still evident in the time range in which late LTP is evident $(>3 \mathrm{~h})$. Since continuous intracellular recordings for such a long period of time is not technically feasible, intracellular recordings were performed $3-5 \mathrm{~h}$ after HFS application, at the sites at 
which stable fPSPs were evoked in response to repetitive synaptic activation (Fig. $1 B$ ).

The averaged postburst AHP in HFSonly neurons $(3.32 \pm 1.2 \mathrm{mV} ; n=12)$ was significantly smaller $(p<0.05)$ compared with the averaged AHP amplitudes in neurons from control neurons $(5.53 \pm 3.1$ $\mathrm{mV} ; n=16)($ Fig. $2 A, B)$. Figure $2 C$ shows that such HFS-induced AHP reduction was observed throughout the time that elapsed between synaptic stimulation and intracellular recordings. Twenty stimuli applied at $1 \mathrm{~Hz}$ (LFS group) did not have the same long-term effect on the postburst AHP, although a tendency toward AHP reduction was observed. The averaged value after stimulating at this frequency was $4.35+1.11 \mathrm{mV}(n=11)$, which does not differ significantly for the averaged value of the control group ( $p=0.24$ ).

Postburst AHP reduction was not the result of a general change in passive and active membrane properties; resting membrane potential $(-65 \pm 3.5 \mathrm{mV}$ in controls and $-63 \pm 2.7$ after HFS; $p=$ $0.35)$, input resistance $(26.7 \pm 8.7 \mathrm{M} \Omega$ in controls and 28.6 \pm 6.5 after HFS; $p=0.66)$, spike amplitude $(91.1 \pm 18.4 \mathrm{mV}$ in controls and $88 \pm 10.8$ after HFS; $p=0.85)$, and spike width $(1.49 \pm 0.3 \mathrm{~ms}$ in controls and $1.59 \pm 0.26$ after HFS; $p=0.78$ ) did not differ between neurons from the two groups.

HFS-induced long-lasting AHP reduction is protein synthesis dependent

We next examined whether long-lasting AHP reduction is dependent on protein synthesis by testing how protein synthesis inhibitor anisomycin application modulates the effect of high-frequency stimulation. Application of anisomycin by itself did not have an effect of the postburst AHP amplitude; the averaged value of the Ani-only group was $4.89 \pm 2.7 \mathrm{mV}(n=$ $24)$. This value does not differ from that observed in the control group $(p=0.61)$.

When HFS was applied in the presence of anisomycin, it failed to induce AHP reduction. The averaged AHP value in the Aniplus-HFS group was $5.0+1.8 \mathrm{mV}(n=12)$. This value is similar to that obtained in the control and the Ani-only groups ( $p=$ 0.65 ) (Fig. $3 A, B$ ). Such lack of HFS effect was observed at all recording time points after repetitive stimulus application (Fig. 3C). Similar results were obtained with another protein synthesis inhibitor, cycloheximide. The averaged AHP value for neurons recorded 180-345 min after synaptic stimulation in presence of this inhibitor was $4.89+0.76 \mathrm{mV}(n=9)$. This value does not differ from the average values of the control group ( $p=0.56)$ and the Ani-plus-HFS group $(p=0.73)$.

Much like as shown for learning and late LTP (Frey et al., 1988; Meiri and Rosenblum, 1998), the effect of anisomycin on HFSinduced AHP reduction does not occur if the protein synthesis
B

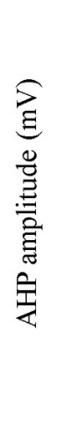

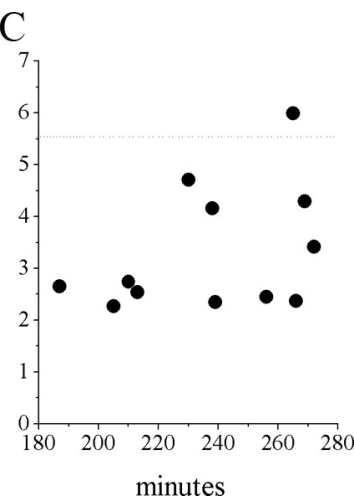

control HFS

minutes

Figure 2. HFS-induced long-lasting AHP reduction. $\boldsymbol{A}$, Postburst AHP measurements in CA1 pyramidal neurons. Neurons were held at membrane potential of $-60 \mathrm{mV}$ and the postburst AHP was generated by a $100 \mathrm{~ms}$ depolarizing current step injection via the group and a neuron from the HFly group are shown. $\boldsymbol{B}$, Averaged AHP amplitude in neurons from the control and groups. Averaged AHP amplitude in the HFS-only group is significantly smaller compared with the control group ( $p<$ $(3-5 \mathrm{~h})$. Reduced AHP, compared with the averaged value of controls (dotted line), was observed throughout this time window.

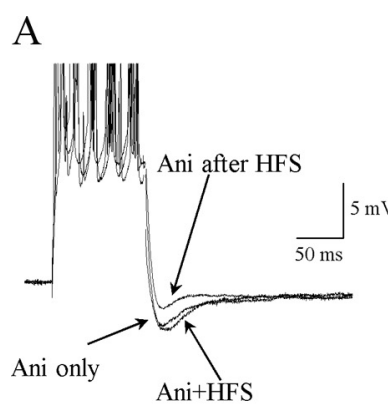

Figure 3. Maintenance of AHP reduction is dependent on protein synthesis. $\boldsymbol{A}$, Examples of AHPs taken from three neurons, representing the Ani-only, the Ani-plus-HFS, and the Ani-after-HFS groups. The AHP in neurons from the Ani-only and the Ani-plus-HFS groups resembles that observed in the control group, whereas the AHP of the neuron taken from the Ani-after-HFS oups ( $\left.{ }^{*} p<0.05\right)$, which do not differ between them. AHP was measured in 24 Ani-only neurons taken from 12 rats, 12

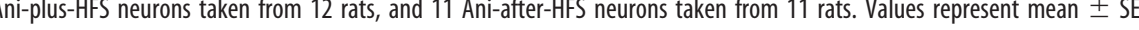
HFS-induced AHP reduction is maintained in the Ani-after-HFS group. Values of AHPs in neurons from the Ani-plus-HFS and the sroups are shown 3-5.5 h after applications of tetanic stimulation. Reduced AHP in neurons from the Ani-after-HFS group was observed throughout this time window. Each dot notes the value of AHP in one cell. For clarity of presentation, 9 of 11 neurons from the Ani-after-HFS group are presented. Values represent mean $\pm \mathrm{SE}$.

blocker is applied an hour after synaptic stimulation. The averaged AHP value in the Ani-after-HFS group was $3.2 \pm 1.3 \mathrm{mV}$ $(n=11)$. This value is significantly $(p<0.05)$ smaller that those obtained for the Ani-only and the Ani-plus-HFS groups (Fig. $3 A, B)$ and is similar to that obtained for the HFS group. This lack of effect was observed throughout the time points tested, from 215 and up to $440 \mathrm{~min}$ after repetitive stimulus application (Fig. 3C).

\section{HFS-induced AHP reduction is observed in most sampled neurons}

Since synaptic activation is induced by applying a strong electrical stimulation to the afferent excitatory inputs into the CA1 pyramidal neurons, it is expected that AHP reduction will occur in a significant portion of the pyramidal cell population in the activated area. Indeed, most of the neurons sampled from the two 


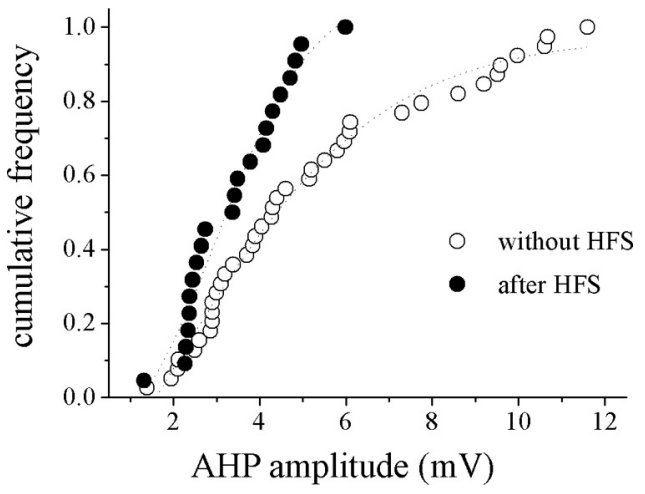

Figure 4. AHP amplitude is reduced in most neurons exposed to HFS without anisomycin. Cumulative frequency distribution of AHP amplitudes in neurons that were not exposed to HFS (control and Ani-only groups) and in neurons that were exposed to HFS without anisomycin presence (HFS and Ani-after-HFS groups). The curve of the AHP amplitudes in neurons exposed to HFS without anisomycin is shifted to the left of the graph that shows AHP values for neurons recorded without previous application of tetanic stimulation.

groups in which HFS was applied without the presence of protein synthesis blocker (the HFS-only and the Ani-after-HFS groups) had smaller AHPs (averaged value of $3.41+1.17 ; n=22$ ) than the average AHP that was sampled in the groups that did not receive any synaptic activation, the control and the Ani-only groups (averaged value of $5.24+2.84 ; n=39$ ). Twenty-one of 22 neurons in the group that was treated with HFS without a protein synthesis blocker had an AHP with amplitude lower than the average recorded in neurons that did not receive synaptic stimulation. A cumulative frequency distribution of AHP amplitudes is shown in Figure 4. With each point representing one cell, it is noticeable that the reduction of the averaged AHP amplitude after HFS is a result of reduction in AHP in most of the sampled neurons. Hence, AHP reduction is widely distributed throughout the neuronal population after application of a strong tetanic stimulation, rather than being restricted to a small portion of the cells.

\section{Discussion}

The notion that memory has different temporal phases rises from behavioral, pharmacological, and molecular correlates and electrophysiological measurements. Memory consolidation is defined as the time after acquisition that memory is still susceptible to distractions, such that would impair obligatory protein synthesis-dependent processes (Abraham and Williams, 2008; Alberini, 2008; Costa-Mattioli et al., 2009). Protein synthesis inhibitors can potentially affect different cellular processes in different cells within the brain, including neurons, glia, and the vascular system. To date, the behavior-relevant role of protein synthesis inhibitors was studied extensively in relation to synaptic function (Abraham and Williams, 2008; Alberini, 2008; CostaMattioli et al., 2009). Our data show that protein synthesis is also crucial for the maintenance of experience-dependent modification of neuronal excitability.

Long-lasting learning-induced enhancement of neuronal excitability has been shown in CA1 hippocampal neurons after classical conditioning of the trace eyeblink response (Moyer et al., 1996), the Morris water maze task (Oh et al., 2003), and olfactory-discrimination learning (Zelcer et al., 2006). This enhanced excitability is manifested in reduced spike frequency adaptation in response to prolonged depolarizing current applications, which results from postburst AHP reduction (Madison and Nicoll, 1984; Moyer et al., 1996; Zelcer et al., 2006).
Long-term reduction in the slow AHP can be also induced in CA1 pyramidal neurons by synaptically released glutamate, evoked by tetanic stimulation of the Schaffer collateral and commissural fibers (Melyan et al., 2002). Here, we show that such synaptic activation-induced postburst AHP reduction requires protein synthesis for its long-term maintenance. Moreover, such protein synthesis is crucial in a time window similar to the time frame in which late-phase LTP and long-term memory are disrupted by protein synthesis inhibitors.

\section{Long-lasting maintenance of HFS-induced AHP reduction}

Biophysical properties underlying neuronal excitability are best studied with two techniques: whole-cell patch-clamp and intracellular recordings with sharp electrodes. Unfortunately, both techniques do not allow continuous recordings for periods of many hours. Because of this technical constraint, the mechanism underlying postburst AHP reduction have been studied to date at two time windows. The first, during and up to $45 \mathrm{~min}$ after HFS application (Melyan et al., 2002, 2004), and the second, after 1 to several days after behavioral manipulations (Moyer et al., 1996; Zelcer et al., 2006). The combination of these two approaches leaves the time window of several hours after synaptic activation, when protein synthesis-dependent processes are expected to occur (Krug et al., 1984; Otani et al., 1989; Frey et al., 1993, 1988; Nguyen et al., 1994), unexplored. To cover this crucial phase, we recorded from pyramidal neurons 3-7 h after application of high-frequency synaptic stimulation to their afferent glutamatergic synapses.

Indeed, such a treatment results in an across-the-board reduction of the postburst AHP in virtually all cells to which HFS was applied without protein synthesis blockers. Thus, HFS-induced postburst AHP reduction in brain slices is not temporally restricted for tens of minutes but may proceed for longer, much like how early LTP develops into late LTP.

\section{Role of protein synthesis in maintaining enhanced neuronal excitability}

It is widely accepted that induction and maintenance of longterm activity-dependent synaptic plasticity involves modulation of the excitatory synaptic connection "hardware" and that this process requires a critical phase of protein synthesis (for review, see Sorra and Harris, 2000; Yuste and Bonhoeffer, 2001). Here, we show a protein synthesis-dependent process that results with a physiological rather than a morphological change. Such protein synthesis seems to be completed within an hour after HFS application; anisomycin does not prevent AHP reduction if applied after this time interval. Notably, it has been shown that protein synthesis is also required for a different form of intrinsic plasticity, termed intrinsic excitability-LTP (Xu et al., 2005). This enhanced long-lasting excitability affects the action potential threshold and is attributed to a shift in the activation curve of the voltage-gated sodium channel. It does not persist for many hours if protein synthesis blocker is present during stimulus application (Xu et al., 2005).

Do the newly synthesized protein(s) affect the AHP-generating channels directly? Previous studies show that the maintenance of AHP reduction and enhanced neuronal excitability are dependent on the cAMP and PKA (protein kinase A) pathways (Lopez de Armentia et al., 2007; Oh et al., 2009), as well as on persistent PKC and extracellular signal-regulated kinase (ERK) activation (Seroussi et al., 2002; Cohen-Matsliah et al., 2007). PKC and ERK are also essential for the induction of such AHP reduction (Melyan et al., 2002; Grabauskas et al., 2007). Thus, it is 
likely that synaptic activity-induced protein synthesis is required for maintaining the ERK and PKC system activity rather than affecting the potassium channel itself.

In conclusion, our data show that activity-induced longlasting modulation of intrinsic neuronal properties, such that result with enhanced neuronal excitability, requires protein synthesis that occurs during a specific time window after synaptic activation. In that respect, persistent changes in the membrane properties of pyramidal neurons resemble long-term changes in synaptic transmission.

\section{References}

Abraham WC, Williams JM (2008) LTP maintenance and its protein synthesis-dependence. Neurobiol Learn Mem 89:260-268.

Alberini CM (2008) The role of protein synthesis during the labile phases of memory: revisiting the skepticism. Neurobiol Learn Mem 89:234-246.

Brosh I, Rosenblum K, Barkai E (2006) Learning-induced reversal of the effect of noradrenalin on the postburst AHP. J Neurophysiol 96:17281733.

Cohen-Matsliah SI, Brosh I, Rosenblum K, Barkai E (2007) A novel role for extracellular signal-regulated kinase in maintaining long-term memoryrelevant excitability changes. J Neurosci 27:12584-12589.

Costa-Mattioli M, Sossin WS, Klann E, Sonenberg N (2009) Translational control of long-lasting synaptic plasticity and memory. Neuron 61:10-26.

Davis HP, Squire LR (1984) Protein synthesis and memory: a review. Psychol Bull 96:518-559.

Disterhoft JF, Wu WW, Oh M (2004) Biophysical alterations of hippocampal pyramidal neurons in learning, ageing and Alzheimer's disease. Ageing Res Rev 3:383-406.

Dudai Y (2004) The neurobiology of consolidations, or, how stable is the engram? Annu Rev Psychol 55:51-86.

Frey U, Krug M, Reymann KG, Matthies H (1988) Anisomycin, an inhibitor of protein synthesis, blocks late phases of LTP phenomena in the hippocampal CA1 region in vitro. Brain Res 45:57-65.

Frey U, Huang YY, Kandel ER (1993) Effects of cAMP simulate a late stage of LTP in hippocampal CAl neurons. Science 260:1661-1664.

Grabauskas G, Lancaster B, O'Connor V, Wheal HV (2007) Protein kinase signalling requirements for metabotropic action of kainite receptors in rat CA1 pyramidal neurones. J Physiol 579:363-373.

Krug M, Lössner B, Ott T (1984) Anisomycin blocks the late phase of longterm potentiation in the dentate gyrus of freely moving rats. Brain Res Bull 13:39-42.

Lopez de Armentia M, Jancic D, Olivares R, Alarcon JM, Kandel ER, Barco A (2007) cAMP response element-binding protein-mediated gene expression increases the intrinsic excitability of CA1 pyramidal neurons. J Neurosci 27:13909-13918.

Madison DV, Nicoll RA (1984) Control of the repetitive discharge of rat CA1 pyramidal neurones in vitro. J Physiol 354:319-331.

Manahan-Vaughan D, Kulla A, Frey JU (2000) Requirement of translation but not transcription for the maintenance of long-term depression in the CA1 region of freely moving rats. J Neurosci 20:8572-8576.

Meiri N, Rosenblum K (1998) Lateral ventricle injection of the protein synthesis inhibitor anisomycin impairs long-term memory in a spatial memory task. Brain Res 789:48-55.

Melyan Z, Wheal HV, Lancaster B (2002) Metabotropic-mediated kainate receptor regulation of IsAHP and excitability in pyramidal cells. Neuron 34:107-114.

Melyan Z, Lancaster B, Wheal HV (2004) Metabotropic regulation of intrinsic excitability by synaptic activation of kainate receptors. J Neurosci 24:4530-4534.

Moyer JR Jr, Thompson LT, Disterhoft JF (1996) Trace eyeblink conditioning increases CA1 excitability in a transient and learning-specific manner. J Neurosci 16:5536-5546.

Nguyen PV, Abel T, Kandel ER (1994) Requirement of a critical period of transcription for induction of a late phase of LTP. Science 265:1104-1107.

Oh MM, Kuo AG, Wu WW, Sametsky EA, Disterhoft JF (2003) Watermaze learning enhances excitability of CA1 pyramidal neurons J Neurophysiol 90:2171-2179.

Oh MM, McKay BM, Power JM, Disterhoft JF (2009) Learning-related postburst afterhyperpolarization reduction in CA1 pyramidal neurons is mediated by protein kinase A. Proc Natl Acad Sci U S A 106:1620-1625.

Otani S, Marshall CJ, Tate WP, Goddard GV, Abraham WC (1989) Maintenance of long-term potentiation in rat dentate gyrus requires protein synthesis but not messenger RNA synthesis immediately posttetanization. Neuroscience 28:519-526.

Power JM, Wu WW, Sametsky E, Oh MM, Disterhoft JF (2002) Age-related enhancement of the slow outward calcium-activated potassium current in hippocampal CA1 pyramidal neurons in vitro. J Neurosci 22:7234-7243.

Rosenblum K, Futter M, Voss K, Erent M, Skehel PA, French P, Obosi L, Jones MW, Bliss TV (2002) The role of ERKI/II in late phase LTP. J Neurosci 22:5432-5441.

Saar D, Barkai E (2003) Long-term modifications in intrinsic neuronal properties and rule learning in rats. Eur J Neurosci 17:2727-2734.

Saar D, Grossman Y, Barkai E (1998) Reduced after-hyperpolarization in rat piriform cortex pyramidal neurons is associated with increased learning capability during operant conditioning. Eur J Neurosci 10:1518-1523.

Sajikumar S, Frey JU (2003) Anisomycin inhibits the late maintenance of long-term depression in rat hippocampal slices in vitro. Neurosci Lett 338:147-150.

Schwindt PC, Spain WJ, Foehring RC, Chubb MC, Crill WE (1988) Slow conductances in neurons from cat sensorimotor cortex in vitro and their role in slow excitability changes. J Neurophysiol 59:450-467.

Seroussi Y, Brosh I, Barkai E (2002) Learning-induced reduction in postburst after-hyperpolarization (AHP) is mediated by activation of PKC. Eur J Neurosci 16:965-969.

Sorra KE, Harris KM (2000) Overview on the structure, composition, function, development, and plasticity of hippocampal dendritic spines. Hippocampus 10:501-511.

Thompson LT, Moyer JR Jr, Disterhoft JF (1996) Transient changes in excitability of rabbit CA3 neurons with a time course appropriate to support memory consolidation. J Neurophysiol 76:1836-1849.

Xu J, Kang N, Jiang L, Nedergaard M, Kang J (2005) Activity-dependent long-term potentiation of intrinsic excitability in hippocampal CAl pyramidal neurons. J Neurosci 25:1750-1760.

Yuste R, Bonhoeffer T (2001) Morphological changes in dendritic spines associated with long-term synaptic plasticity. Annu Rev Neurosci 24:1071-1089.

Zelcer I, Cohen H, Richter-Levin G, Lebiosn T, Grossberger T, Barkai E (2006) A cellular correlate of learning-induced metaplasticity in the hippocampus. Cereb Cortex 16:460-468.

Zhang W, Linden DJ (2003) The other side of the engram: experience-driven changes in neuronal intrinsic excitability. Nat Rev Neurosci 4:885-900. 